\title{
SUCCESS FACTORS FOR RURAL RESILIENCE: THE CASE OF SMALL SCALE FARMS IN ITALY
}

\author{
Rafaela Reznik Rocha ${ }^{1 *}$ \\ ${ }^{I}$ Institute of Systems Sciences, Innovation and Sustainability Research, University of Graz, Austria
}

\begin{abstract}
This research is based on the empirical and theoretical case study of Garfagnana Valley, a mountainous region near the Italian coast where traditional and innovative rural methods of small scale farms prevail. Although these farmers present big resilience to persist with their activities, they constantly face many challenges (weak policies, population ageing, market pressures, etc.). To protect their rural activities without expanding their scale of productivity, a diversity of farm strategies emerged. Product diversification, other gainful activities besides farming, attractive farming lifestyles, and high-quality products are some alternatives which enable many small scale producers to maintain their rural practices. Yet, small scale production needs specific kinds of agricultural logistics and dynamics, such as an adapted food supply chain. The aim of this research is to analyze the factors which enhance the success of small scale farms in the area studied. Accordingly, the main actors involved and the contextual and external conditions for preserving the agricultural practices are identified. By contributing to a better understanding of the rural sector, this work provides an outlook on small scale farms and its main success factors, creating value for academic literature and for application in the social scope.
\end{abstract}

Keywords: agri-food systems; Italy; rural sector; small scale farms

\section{Introduction}

Over the last decade the rural sector has been in crisis, especially when concerning agricultural practices. Rural production have decreased, contributing less to national GDPs, reducing farmers' incomes and rural employment rate. Nevertheless, economies of scale of big and traditional producers are maintained by advanced modern techniques and favorable schemes (Moragues-Faus, 2014). In Europe, small scale farms have an important role due to employment of a big share of the population, and by caring for environmental and social demands (De Castro et al., 2014). Despite competition and major challenges encountered by low intensity producers such as market pressures, weak policy protection, and population ageing, small scale rural holdings persist. Besides, small scale farms need specific logistics and agricultural dynamics. To enable these processes, food supply chain must be adapted to farms' contextual realities, including its technology, labor structure, farming activities, relationships among farmers and between producers and other important actors (administration, local community, cooperatives, associations, etc.). Thus, to maintain their rural practices, a diversity of farm strategies emerged. Moreover, within the Mediterranean area, some cultural and environmental aspects embed characteristic values to the region, acknowledging it with internationally perceived high-quality food products (Moragues-Faus, 2014; Galli, 2015). Among these aspects, there is a manifold list of reasons for the small scale farmers to persist with their existence, such as a strong link to their territories. The preference was given to high added value produce rather than enlarging the production, which promotes sustainability in multiple dimensions (environmental, social, and economic).

To support low intensity production and maintain population within rural areas, not only novel agricultural methods are needed, but also policies from responsible authorities shall be attractive. Public policies shall ensure 
enough funding and non-monetary (land, trainings, etc.) support to rural holdings enabling their development. However, small scale farms still lack adequate attention from authorities (ECVC, 2015).

To comply with the concept of food security, where safe and nutritious food should be available to all people at all times (FAO, 1996), gaps among the rural sector need to be fulfilled. To the European Union's Common Agricultural Policy (EU's CAP), small and semi-subsistence farms are many times seen as relatively 'invisible' (Dwyer, 2014). Therefore, this research narrowed its case study taking the Garfagnana Valley as an example to explore the challenges and potentials of small scale farms, creating an opportunity to improve rural development practices. To guide this work, the research followed the leading question: "Which are the main factors that influence small scale farms strategies within the Garfagnana Valley?". The aim of this paper is to provide an analysis of the key success factors which enhance the effectiveness of small scale farms projects in rural area, being potentially useful for further studies and policies related to its social scope.

This paper consists of five sections. First, the introduction brings in the background and main objective of the research. Second, the methodology presents the research methods used. Third, the results are exposed within eight subsections. Each subsection describes an important dimension among the findings of the study. Forth, the discussion enhances some key aspects brought upon the results. Finally, the conclusion provides a summary and recommendations.

\section{Methodology}

This research was built on a theoretical base combined with an empirical work. The theoretical approach was established by scientific literature review and analysis. The articles reviewed were used to create a framework so that an analysis could be empirically performed during the case study. The documents were selected according to the intention of narrowing down the scope of the research topic from rural development to small scale farms. Articles that approached either broadly or more in details different governance models over the rural sector were used to increase the research background with relevant information about the core topic of this work. The literature review focused on the main agricultural challenges over the past decades, seeking to understand the context behind the rural sector. The search was concentrated on agricultural lands and on rural development policies within the Mediterranean region. By that, the main actors involved, and the contextual conditions of small scale farms could be identified. The bibliography of this work illustrates mostly Italian and other European countries' cases to have a deeper perspective of the region chosen for the case study.

The empirical basis took place in the Garfagnana Valley, within the province of Lucca, in the Tuscany region. It is characterized by being a mountainous region of central Italy, near the coast. This location exhibits a majority of small and semi-subsistence rural households, where innovative and traditional techniques are used for their agricultural activities. By these reasons, the Garfagnana Valley was chosen as a case study, being an example for other regions with a similar context. The methodology used for the empirical work was organized by the Rapid Rural Appraisal (RRA) method with observational research field visits, in-depth face to face semistructured interviews, and two focus groups of local farmers and local institutions respectively, conducted in July 2017. The RRA, a method which emerged in the 1970's, is a merger of data collection techniques to understand the ongoing rural situation (Chambers, 1981). Besides the participants of the focus groups, a total of sixteen farms located within the Garfagnana Valley were subjected to interviews and field visits. The interviews and questionnaires were conducted on both employees and landowners from all rural businesses involved.

The focus question "Which are the main factors that influence small scale farms strategies within the Garfagnana Valley?" was elaborated based on the analyzed policies, modes of governance, main actors involved, and the relations between them. The review of the articles provided at first, the claims which are necessary to rural development, at second, the success criteria which influence the effectiveness of the implementation of small scale farms, and at last, the dependent and independent variables identified together with a discussion of how they have been selected as explanatory factors. 
A bottom up approach was adopted by means of creating the research question and the interview questionnaire for the field visits and focus groups. The interviews' questionnaire dealt with understanding the main relationships between farmers and the administration (authorities), and between farmers and other actors (nongovernmental), and with understanding the support (monetary and non-monetary) farmers received from administration and from other stakeholders (from local to international level).

\section{Results}

\section{Challenges}

To keep up with market demands, small scale farms are compelled to promote changes in their farming systems. Most frequently, farmers encounter limitations such as strict regulations, land tenure arrangements, and constraint financial capacity. Therefore, radical shifts are uncommonly made to achieve necessary changes. Rather, already existing farming systems are gradually adapted to new needs by exploring their own households labor force to enable commercialization of their products. Thus, each advancement is added until a meaningful modification occurs to the farming system (Dyer, 2013). In parallel, large scale farms have the benefit of having most regulations outlined for their necessities. Big supply chains are most common within the rural sector and financially favor big sized production with less costs to commercialization, enabling economies of scale and facilitating access to credit, knowledge, and inputs. Accordingly, large scale producers may easier achieve standard requirements, quality labels, accurate delivery schedule, and other important conditions for a successful rural enterprise (ECVC, 2015).

Another concern, especially within small scale producers, is the ageing of rural households. In Europe, only $6 \%$ of the rural activities are taken over by citizens with less than 35 years old (De Castro et al., 2014). In such a way, worries about attracting youngsters back to the rural sector are frequent among farmers.

\section{Strategies for resilience}

To avoid being crushed by big producers, small scale farmers engage in partnerships and agreements among themselves and with private businesses. These collaborations aim to receive non-monetary support such as trainings, technical assistance, marketing reinforcement, and inputs as an exchange for produce supply. Backed up by these networks, small sized farms gain the chance to maintain their products within the commercial trade (Dyer, 2013). Small scale producers tend to maintain an entire production system, preserving high value and product variety. Within the studied region, some cultural and environmental aspects are embedded as characteristic values, acknowledging it with internationally perceived high-quality food products (Galli et al., 2015). Likewise, preference is given to high added value produce rather than production enlargement.

Multifunctionality of farming systems is also adopted as one manner of livelihood strategy to keep rural practices alive among small scale farmers without necessarily increasing the productivity size. Pluri-activity, having a gainful activity besides farming such as part-time employment in the nearest town, as well as product diversification, became potential options to financially maintain the rural businesses. This combination can be positive since non-agricultural gains are often used to develop the agricultural practice (Ascione et al., 2012; Moragues-Faus, 2014).

Moreover, in order to make rural lifestyle once again attractive to youngsters and promote diversified nonagricultural services, social development projects emerge within small farms (Peters and Gregory, 2014). Social farming can be exemplified by rural practices which include refugees, physically and mentally disabled, and other sorts of needy people. In addition, agritourism and educational projects such as kindergarten farming, are also found as primary activities of some rural holdings which aim to innovate rural habits making them more appealing for young people. 


\section{Contextual and external conditions}

Within the main factors which influence the small scale farmers' strategies in the Garfagnana Valley, some contextual conditions were identified. Among all are such as financial reasons (profitable gains, subsistence, etc.), pleasure (hobby, self-consumption, etc.), traditional values (emotional affection to property), convenience (independence, self-sustaining, etc.), and satisfaction (ego, reputation, etc.).

Along with the contextual conditions, several external aspects are in like manner determinants to maintain the agricultural tradition, since a multi-dimensional environment is common to the region (Grando, 2017). With this characteristic, a list of external conditions which directly or indirectly may affect the agricultural progress are: ecological (weather events, pollution, biodiversity, shortages, etc.), socio-institutional (legal and illegal practices, administration efficiency, auditions, controls, etc.), socio-demographic (urbanization flow, lifestyles, education, generational renewal, etc.), financial (credit access, speculation, cash flow, intermediaries, risk management, etc.), technological (techniques, infra-structure, accessibility, digital services, etc.), demand (patterns, value chains, market concentration, competitors, price volatility, etc.), accessibility (workforce, seeds, land, energy, irrigation, fertilizers, etc.), and legislative (health and hygiene, spatial and development plans, taxation, trading, conservancy, etc.). Each external condition can be applicable and relevant to different levels of society such as global, national, regional and local level, or as a complex dimension cross-scalar (e.g., global warming).

All these influencing conditions are indeed the personal perception of individuals immerse in the context since these factors are socially constructed among the producers' networks. Hence, these aspects may influence the farmers' decision-making processes, either immediately or as an effect of a longer causal chain (Grando, 2017).

\section{Embeddedness}

In Italy, the cultural, ecological, and historical aspects involving the relationship with the food system are in many cases key factors to explain non-economic motivations of decision making processes within the rural sector. Thus, the social and territorial values are determinants for changes and assumed as embedded meanings in the Italian society, widely justifying the maintenance of low productivity farms in the area. The concept of embeddedness embraces both vertical and horizontal dimensions. The former considers the regulations, institutions and political context, and the latter takes into account the local, spatial and cultural context (Moragues-Faus, 2014). In this manner, social and territorial embeddedness are important motive forces when it comes to farms' strategic decisions.

\section{Relationship with governmental actors}

Most survey participants report weak communication and difficult relationship with the administration authorities. In this context, bureaucracies showed up as being a barrier for development and knowledge transfer, exemplified by the difficulty of product and label certification due to high costs, overstated standards, and strict regulations (e.g., organic production). Among the interviews, the only level of governance which was said to have a stronger and closer relationship with the rural holdings was the Union of Municipalities. Besides this, a difficulty encountered was the lack of legislation for some innovative activities such as social farming with kindergarten. To adapt to that, farms need to be flexible and comply with many regulations already in place for different activities.

Nevertheless, it is observed that the governmental bodies also help to improve relationships between local actors, enabling the creation of important networks for the producers. In addition, the local health authority is a stakeholder who is constantly present and auditing farms' production, conditions and produce quality. The producers agree that auditing is important to maintain the quality of the products, however, the authorities are perceived as sometimes excessively present and with exaggerated regulation standards. Likewise, farmers' 
relationship with the social service office is noticed in a regular basis since many rural activities in the Garfagnana Valley are considered social farming.

\section{Relationship with non-governmental actors}

Farmers' relationship with local institutions and among small scale producers is described as positive by most survey participants. Many of these relationships are said to be based on friendship connections. A variety of arrangements are reported such as fairs, partnerships of producers with local restaurants, distributors, shops, and with the solidarity purchasing group. These engagements facilitate the advertisement and commercialization of local brands and products. To enable such networks, associations and cooperatives of local producers emerged.

The relationship among farmers is perceived by themselves as an important factor for sharing traditional knowledge, which has a special meaning in the rural sector since much is transmitted across generations. Another important actor is the religious charity group Caritas, which has a great influence in the region by promoting social programs within the communities. Caritas enables donations to be delivered to innovative development projects, providing good opportunities for the Garfagnana Valley.

When referring to competitors (producers of the same type and category of products), small scale farmers are open for collaborations and insist on uniting themselves instead of being adversaries. Sticking together is clearly not only important but also necessary for their survival.

Moreover, the marketing and advertisement of most activities is done by word of mouth, where the perception of the consumer is transmitted to the next one and further on. As a marketing strategy, the producers persist with informal relations, sale points and partnerships, in order to sustain recognition of local brands and products within consumers, even when the action is not profitable. Technological platforms are also strategies used for funding and advertisement opportunities such as crowdsourcing, crowdfunding, social and informational platforms commercially employed.

\section{Monetary support}

Financial support usually derives straight from governmental authorities. Some types of subsidies aim to pay salaries of those who are employed in social projects such as people with special disabilities and refugees. The release of loans and grants is another type of monetary support which facilitates access to necessary equipment, construction material and other devices. In order to be eligible to receive these allowances, farmers need to fulfill an application and comply to established selection criteria. This judgement can be elucidated as, for example, the priority of funding female rural entrepreneurs and farmers younger than 40 years old. Although some types of rural activities do not undergo any sort of funding opportunities, they can be benefited by tax exemptions or tax reductions if in accordance to applicable regulation, such as agritourism practices.

The European Union (EU) is the main actor providing monetary support opportunities for the rural sector. The financial support, specially the EU's CAP provisions, enhances effectiveness of small farms by increasing its economic performance, independent of their business characteristic. So, both conventional and diversified, as well as multifunctional producers are positively affected by monetary investments (Ascione et al., 2012). Although these subsidies are determinants for the success of the rural businesses, the complaints about the funds and grants being delayed and taking too long to be released is constantly noticed among the local farmers. Thus, despite the incentives received, most farmers perceive investments as a burden they have to face alone. When asked how they succeed with their rural activities and overcome the financial challenges, Angela Pieroni, an apiculture farmer (owner of Miele della Valle del Serchio) who participated of the research survey mentioned: "We are basically walking by our own feet". 


\section{Non-monetary support}

Trainings and specialized services are mostly provided by the administration. Some of these practices are exemplified by agronomists' support for plantations and biodiversity conservancy, psychologists' assistance for employees with mental disorders and physical disabilities, and coaches for refugees. The trainings usually aim to provide specific qualification to producers. Most of these educational activities have a cost for the participants, are usually compulsory and audited with an attendance list by the authorities. Once more, the charity group Caritas is regularly present providing allowances, especially for social projects within the rural sector.

Furthermore, some activities receive non-monetary support such as land, seeds from the seed bank (to incentive cultivation of different plant species), and specific animal breeds. The latter can be exemplified by the incentives given to farmers to raise Garfagnina Bianca, a breed of small domestic sheep considered endangered, which is typical from the Garfagnana Valley (Degl'Innocenti et al., 2003). Collaborations of farmers with educational institutions to develop research and stimulate cultivation of seed varieties and animal species are also existing.

\section{Discussion}

The shortfall of investments, resources and policies addressed to small scale producers leads to a debate on why to safeguard this type of rural practice. In this manner, it is important to discuss the reasons why small scale farms should be protected. Primarily, these producers cater rural employment opportunities, as well as act as social shock absorbers by engaging disabled and marginalized people into their projects. With alternative and modern lifestyles, innovative ventures are also settlement of youngsters, providing them with a sense of purpose to regain agricultural activities and participate in the social and economic dynamics of the rural sector. Shorter supply chains enable fresher produce and greater product variety, enhancing food quality, safety and security. Besides that, adapted production, processing, and product distribution help develop innovation capacity of the holdings involved. In addition, there is constant fostering of biodiversity conservancy and cultural heritage by protecting fauna and flora species and endorsing high quality products, which is usually directly linked to small farms' local identity (ECVC, 2015).

To fulfill the concern about preservation of small rural producers, the EU's CAP affirms that the needs and potentialities of small and semi-subsistence farms are respected as much as those from big producers, by providing enough monetary and non-monetary support (Peters and Gregory, 2014). The policy framework evolved to embrace not only the agroindustry needs, but also the small scale farms' requirements such as shorter supply chains, technology, and environmental services. It also embraces some rural networks which aim to provide knowledge transfer and development by means of cooperation involving both governmental and nongovernmental stakeholders. However, to manage the policy, the European Member States have the right to intervene and decide whether they want to invest by direct monetary payments or by other types of improvements such as training opportunities (ECVC, 2015). This organization mechanism demonstrates the decentralization mode behind the decisions taken. Thus, the event of planning where, in what, and how the investments in the rural sector are made are subject to decisions which not always favor the small producers. To provide a better food chain organization to small scale farms, it is necessary to gather not only adapted supply systems but also promote quality schemes, local markets, and producers' network (Peters and Gregory, 2014). In this sense, international policies must recognize the importance of the small scale producers and support them accordingly. Additionally, proper organizational infrastructure and political will is determinant to maintain the programs which stimulate local agriculture since they can enhance healthy lifestyles in communities. Projects such as those which target social and economic tools strengthen local communities by promoting yield increase, income generation and sustainable livelihoods, not only to farms but also to rural non-farms holdings (Godfray et al., 2010). 
Besides that, the inclusion of farmers into the decision-making processes of their local communities contributes to bigger commitment on development plans (Peters and Gregory, 2014). In this context, collaborative networks play an important role to strengthen the connection between farmers and authorities, as much as to promote sources of employment in rural areas. Thus, cooperatives and other forms of collaborations between the entrepreneurial activities observed among the rural holdings enhance social and cultural capital, enabling income generation to the region, while a financial flux comes and goes through rural economy, welfare state and part time farming, strengthening the local economy (Moragues-Faus, 2014). Accordingly, the integration among farmers is important for strategic achievements since small scale producers aim to reach big markets to commercialize their products and to promote their regions' high-quality food recognition worldwide. Therefore, trust and short food chains are valorized and fundamental to build up relationships, sell produce, and endorse rural business development. To achieve these results, most of the farmers in the Garfagnana Valley apply innovative models to their rural businesses, prioritizing valorization and differentiation of their products. In parallel, the EU's CAP incentivizes the construction of networks involving local stakeholders for rural development and competitiveness of the sector due to the policy's emphasis on the importance of innovation and knowledge (Ascione et al., 2012).

\section{Conclusion}

Bounded by a crisis in the rural sector and shallow investments focusing small and semi-subsistence farms, this research shows that the Garfagnana Valley can be considered as an empirical case study to investigate the main reasons why small rural households persist with their agricultural practices. A scientific literature review followed by a RRA methodology were conducted, including primary data collection to understand the ongoing rural situation of the selected region.

The results showed that to keep up with market demands, small farms require modifications of their farming systems. However, to achieve the necessary changes, limitations are usually encountered. Thus, shifts are mostly done in a short pace, with a gradual adaptation to novel needs for the farming systems (Dyer, 2013). In parallel, most regulations and supply chains are outlined for large scale producers, benefiting them with less costs to commercialization, economies of scale and easier access to credit, knowledge, and inputs (ECVC, 2015). Another concern is the population ageing of rural areas since most rural households grasp citizens older than 35 years (De Castro et al., 2014). As a reaction to these challenges many strategies emerged such as local networks where partnerships among a variety of stakeholders play a major role (Dyer, 2013). Additionally, small scale producers favor an entire production system, preserving high quality and product variety, giving preference to high added value produce rather than production enlargement. Besides that, multifunctionality of the farming systems as well as attractive and innovative rural lifestyles are other livelihood strategies which maintain rural businesses (Ascione et al., 2012; Moragues-Faus, 2014).

On this backdrop, contextual and external conditions are determinants to influence small scale farms' strategies. Amid these circumstances there are personal financial matters and accessibility, pleasure, traditional values, convenience, satisfaction, as well as features in the field of ecology, socio-institution, socio-demography, technology, market demand, and legislations. In general, these aspects may promptly or slowly affect the agricultural progress of the region, either straightforward or in a devious way (Grando, 2017). Another critical non-economic motivation of small farms is their strong social and territorial embeddedness, widely justifying the maintenance of low productivity farms in the area.

Exploring the governance mechanisms behind this scenario, the farmers' relationship with governmental actors is roughly more arduous than the relationship among non-governmental actors. Hence, networking and collaboration is paramount for the maintenance of the rural households. Since most activities are innovative and committed to social projects, organic agriculture and permaculture, the holders perceive themselves as a bridge to future generations. This attitude reveals bottom up approaches necessary for the local development since they 
lack enough support from authorities. Concerning monetary provisions, usually provided by the EU authorities, few fund opportunities are available upon rigid selection criteria. However, many complaints are made regarding grants being delayed and taking too long to be released. Non-monetary support such as trainings and specialized services are also mostly provided by the administration. Regularly, trainings are compulsory, not free of charge, and have the farmers' attendance audited.

In this manner, there are reasons why small scale farms should be protected. Among them: rural employment opportunities, settlement of youngsters, enhancement of food quality, safety and security, innovative capacity building, biodiversity conservancy, and cultural heritage (ECVC, 2015).

To enable sustainable rural development, some challenges need to be overwhelmed. Hence, this research addresses some recommendations for improvement of the sector. Agricultural dynamics of small scale farms need to be acknowledged by means of adapting food supply chains, including its technology, labor structure, farming activities, and relationships among stakeholders. Communication and exchange of information between producers and all levels of the administration need to increase, as well as regulations aimed at small holdings need to be outlined to their capacities. The involvement of producers into decision-making creates bigger commitment for development plans. Thus, public policies must include wide participation of rural holders in their governance. In addition, encouragement of collaborative networks among local stakeholders should be prioritized to enhance rural activities, with endorsement to educational projects which raise awareness on food quality, safety and security.

This study unveils the importance of considering an interdisciplinary approach to understand attitudes of small scale farmers in their rural context. It designs an introductory pathway for further studies, creating value for academic literature, and provides recommendations which can be applied in the social scope.

\section{Acknowledgements}

Thanks to the University of Pisa, in special Francesco Di Iacovo, Simona D'Amico, Paola Scarpellini and Francesca Cofini for their valuable insights and time devoted on the process of conducting the Summer School 2017 which enabled the development of this work. The researcher is also indebted to the colleagues Yasmine Abdelaziz, Bianca Souza, and Juliana Luiz who have shared their thoughts for the composition of this study. A particular gratitude to the farmers, associations, and local institutions of the Garfagnana Valley who participated in the case study and shared their moments and personal opinions. Finally, this research would not have been possible without the support of the University of Graz (Austria), who partially funded this study program through its "Short-term Scientific Work (KUWI) Scholarship".

\section{References}

Ascione, E., Henke, R., \& Vanni, F., 2012. Small farms in Italy: public support, diversification and economic sustainability. Problemy Drobnych Gospodarstw Rolnych, (1), 31-42.

Chambers, R., 1981, Rapid rural appraisal: rationale and repertoire. Public administration and development. 1 (2), 95-106.

De Castro, P., Adinolfi, F., \& Capitanio, F., 2014. Family farming. Issues and challenges in the reformed common agriculture policy. Economía Agraria y Recursos Naturales, 14(1), 169-176.

Degl'Innocenti, P., Diaz Rivera, P., Martini, A., Perez Torrecillas, C., Conti, S., \& Giorgetti, A., 2003. Phenotypic diversity of Tuscany's endangered sheep breeds: a descriptive approach. Italian Journal of Animal Science, 2(suppl.1), 560-562.

Dwyer, J., 2014. CAP Reform Proposals for Small and Semi-subsistence Farms. EuroChoices, 13(1), 31-35.

Dyer, K. W., 2013. Supporting small farmers to commercialise. Future Agricultures, FAC CAADP Policy Brief 11. 
ECVC - European Coordination Via Campesina, 2015. How can public policy support small-scale family farms? Booklet.

FAO - Food and Agriculture Organization of the United Nations, 1996. Rome Declaration on Food Security and World Food Summit Plan of Action, World Food Summit. Date of access: 09/11/2017. http://www.fao.org/docrep/003/w3613e/w3613e00.htm.

Galli, F., Bartolini, F., Brunori, G., Colombo, L., Gava, O., Grando, S., \& Marescotti, A., 2015. Sustainability assessment of food supply chains: an application to local and global bread in Italy. Agricultural and Food Economics, 3(1), 21.

Godfray, H. C. J., Beddington, J. R., Crute, I. R., Haddad, L., Lawrence, D., Muir, J. F., Pretty, J., Robinson, S., Thomas, S. M., \& Toulmin, C., 2010. Food security: the challenge of feeding 9 billion people. Science, 327(5967), 812-818.

Grando, S., 2017. Theoretical Framework. Lecture notes. Summer School in Food and Innovation in Rural Transitions: The Tuscany case. University of Pisa.

Moragues-Faus, A., 2014. How is agriculture reproduced? Unfolding farmers' interdependencies in small-scale Mediterranean olive oil production. Journal of Rural Studies, 34, 139-151.

Peters, R., \& Gregory, M., 2014. Networking, Small Farms and EU Rural Development Policy. EuroChoices, 13(1), 36-39. 